\title{
WHAT HAVE MACROECONOMISTS LEARNED ABOUT BUSINESS CYCLES \\ FROM THE STUDY OF SEASONAL CYCLES?
}

Jeffrey A. Miron

J. Joseph Beaulieu

Working Paper 5258 
NBER WORKING PAPER SERIES

\section{WHAT HAVE MACROECONOMISTS \\ LEARNED ABOUT BUSINESS CYCLES \\ FROM THE STUDY OF SEASONAL CYCLES?}

Jeffrey A. Miron

J. Joseph Beaulieu

Working Paper 5258

\section{NATIONAL BUREAU OF ECONOMIC RESEARCH 1050 Massachusetts Avenue \\ Cambridge, MA 02138 \\ September 1995}

Comments from Russell Cooper, Robert Hall, John Shea, Jim Stock, three anonymous referees and participants at the October, 1993 NBER Economic Fluctuations Meeting in Cambridge are appreciated. The paper was originally presented as "Macroeconomics and Seasonal Cycles." Miron gratefully acknowledges support from the Sloan Foundation and the National Science Foundation. The views in this paper do not necessarily reflect those of the Board of Governors, its staff, or the National Bureau of Economic Research. This paper is part of NBER's research programs in Economic Fluctuations and Monetary Economics.

(C) 1995 by Jeffrey A. Miron and J. Joseph Beaulieu. All rights reserved. Short sections of text, not to exceed two paragraphs, may be quoted without explicit permission provided that full credit, including $($ ) notice, is given to the source. 


\title{
WHAT HAVE MACROECONOMISTS \\ LEARNED ABOUT BUSINESS CYCLES \\ FROM THE STUDY OF SEASONAL \\ CYCLES?
}

\begin{abstract}
This paper argues that analysis of seasonal fluctuations can shed light on the nature of business cycle fluctuations. The fundamental reason is that in many instances identifying restrictions about seasonal fluctuations are more believable than analogous restrictions about nonseasonal fluctuations. We show that seasonal fluctuations provide good examples of preference shifts and synergistic equilibria. We also find evidence against production smoothing and in favor of unmeasured variation in labor and capital utilization. In some industries capacity constraints appear to bind.
\end{abstract}

Jeffrey A. Miron

Department of Economics

Boston University

270 Bay State Road

Boston, MA 02215

and NBER
J. Joseph Beaulieu

Mail Stop 82

Board of Governors of the

Federal Reserve System

Washington, DC 20551 


\section{Introduction}

The presence of seasonal fluctuations in aggregate economic activity has concerned macroeconomists for many years (e.g., Kemmerer (1910), Bursk (1931), Kuznets (1933), Macaulay (1938), Burns and Mitchell (1946)). Traditionally macroeconomists regarded seasonal fluctuations as inherently uninteresting, so research on economic fluctuations abstracted from seasonality. Recently, however, macroeconomists have become interested in seasonal fluctuations, and considerable research has examined seasonal fluctuations explicitly (e.g., Ghysels (1988), Barsky and Miron (1989), Chatterjee and Ravikumar (1992), Braun and Evans $(1991,1994)$, Cecchetti, Kashyap and Wilcox (1994)).

In this paper we assess what macroeconomists have learned about business cycles from this renewed examination of seasonal cycles. Section 2 of the paper discusses why accounting explicitly for the seasonal behavior of economic activity can expand understanding of business cycles. The fundamental insight is that in many instances identifying restrictions about seasonal fluctuations are more believable than analogous restrictions about 
non-seasonal fluctuations. ${ }^{1}$ As discussed below, this observation suggests three distinct ways in which explicitly accounting for the seasonal variation in economic data can enhance understanding of non-seasonal variation.

The remainder of the paper reviews some of the most important conclusions about business cycles provided by the study of seasonal fluctuations. Section 3 argues that seasonal fluctuations provide good examples of preference shifts and synergistic equilibria and that these phenomena occur over the business cycle as well. Section 4 explains that seasonal dummy instrumental variables estimation provides evidence against production smoothing and in favor of unmeasured variation in labor and capital utilization. Section 5 examines evidence on the convexity of marginal cost provided by the interactions between seasonal and non-seasonal variation. Section 6 concludes the paper.

\section{Using Seasonal Fluctuations to Understand Busi- ness Cycle Fluctuations}

In this section we explain why accounting for seasonal fluctuations can enhance understanding of business cycle fluctuations. We conduct this dis-

\footnotetext{
1Throughout this paper, we use the terms "non-seasonal" and "business cycle" synonymously. Beaulieu and Miron $(1991,1993)$ defend this approach.
} 
cussion using a simple but familiar model to focus attention on key issues. The model is not meant to subsume all the empirical issues discussed below, merely to provide a framework in which the main principles can be outlined.

\subsection{An Illustrative Model}

The model considered here is a simplified version of the model discussed in Chatterjee and Ravikumar (1992) and Braun and Evans (1994). A representative consumer maximizes the expected present discounted utility of consumption, $C_{t}$, subject to resource constraints,

$$
\begin{aligned}
\max _{C_{t}, L_{t}, I_{t}} E_{0} \sum_{t=0}^{\infty} \theta_{t} \beta^{t} U\left(C_{t}, L_{t}\right) & \\
\text { s.t } Y_{t} & =A_{t} F\left(K_{t}, N_{t}\right) \\
Y_{t} & \geq C_{t}+I_{t} \\
K_{t+1} & =(1-\delta) K_{t}+I_{t} \\
L_{t}+N_{t} & \leq 1
\end{aligned}
$$

Production, $Y_{t}$, depends on capital, $K_{t}$, and labor, $N_{t}$; production can be consumed, $C_{t}$, or invested, $I_{t}$. Total output, the flow of capital, and the total endowment of hours are fixed by the usual accounting constraints. Two shocks, $\theta_{t}$ and $A_{t}$, each of which may contain a deterministic seasonal 
component and a stochastic non-seasonal component, buffet the economy.

Given particular functional forms for preferences and technology, one can estimate this model under appropriate assumptions. As a general rule, however, the identifying assumptions required about the non-seasonal components of $\theta_{t}$ and $A_{t}$ are difficult to assess or understand. This does not mean they are invalid, simply that it is often hard to decide whether one finds these assumptions plausible.

With respect to the seasonal variation, the situation is less difficult. Although one might not wish to assume away all seasonal variation in technology, one can still place bounds on the kinds of seasonal variation that are reasonable. Additionally, although one might not know the seasonality of $\theta_{t}$ exactly, one can imagine that events such as Christmas or other holidays shift the marginal utility of consumption. If one is examining particular goods, other kinds of assumptions might be defensible.

Thus, a priori restrictions on the seasonal properties of $\theta_{t}$ and $A_{t}$ are likely to be convincing, or at least significantly more convincing than the other kinds of restrictions often employed to estimate aggregate models. Assuming this view is correct, one can use seasonal cycles to learn about 
business cycles in at least three distinct ways.

\subsection{Seasonal Fluctuations as Suggestive Phenomena}

The simplest way to use seasonal fluctuations as a way to learn about business cycle fluctuations is to determine the presence or absence of particular phenomena over the seasonal cycle and ask whether the result is informative about the presence or absence of the same phenomena over the business cycle. As an example, consider the question of whether preference shifts are a quantitatively important source of aggregate fluctuations.

Determining the magnitude of preference shifts is difficult because it requires, in effect, consistent estimation of consumer preferences. As a rule, valid instruments for the estimation of these preferences are difficult to find.

Gauging the approximate magnitude of seasonal preference shifts, however, is less difficult. To begin, a priori information suggests that events like Christmas and other holidays shift preferences, either for broad categories of goods or, in some cases, for particular goods. In addition, the magnitude of the seasonality in purchases of many goods is prima facie evidence of such shifts, since the elasticity of substitution or the seasonality of interest rates necessary to generate these fluctuations without preference shifts is 
implausible.

Thus, both a priori reasoning and data imply that preference shifts are an important source of seasonal fluctuations. Does this conclusion alter one's prior about the importance of preference shifts as a source of nonseasonal fluctuations? As a matter of logic, the answer is no. The presence of a particular phenomenon over the seasonal cycle does not necessarily say anything about the business cycle. The following argument, however, suggests that in practice the existence of a phenomenon over the seasonal cycle does increase the likelihood that the same phenomenon occurs over the business cycle.

Consider Figures 1 and 2, which present evidence on the cross-sectional correlation between the amounts of seasonal and the amounts of non-seasonal variation in manufacturing output. Figure 1 presents data for countries, while Figure 2 presents data for industries in the United States. Each figure shows the standard deviation of the seasonal component of industrial production for an industry or country on the horizontal axis and the standard deviation of the non-seasonal component on the vertical axis. ${ }^{2}$

\footnotetext{
${ }^{2}$ The seasonal component is estimated by regressing the growth rates on seasonal dummies and calculating fitted values, while the non-seasonal component is the residual.
} 
The two quantities are strongly, positively correlated. As demonstrated in Beaulieu, MacKie-Mason, and Miron (1992), this result holds for a broad range of aggregate variables, including retail sales, money, prices and interest rates across countries and shipments, inventories, and labor input across industries. The result is robust to a broad range of alternative specifications, including the treatment of stationary stochastic seasonality.

To see why this fact implies that the existence of a particular phenomena over the seasonal cycle implies the presence of the same phenomena over the business cycle, consider the reduced-form equation for an endogenous variable, $y$, that relates it to the exogenous variables $x_{1}$ and $x_{2}$,

$$
y=f_{1} x_{1}+f_{2} x_{2}
$$

where each of $x_{1}, x_{2}$ is the sum of a stationary non-seasonal component and a deterministic seasonal component,

$$
x_{1}=x_{1}^{n}+x_{1}^{s}, \quad x_{2}=x_{2}^{n}+x_{2}^{s} .
$$

Assume for simplicity that one of the exogenous factors is purely seasonal while the other is purely non-seasonal, e.g., $x_{1}^{n}=x_{2}^{s}=0$. Given these assumptions, the amounts of seasonal and non-seasonal variation in $y$ will be positively correlated cross-sectionally under either of two conditions. 
The first condition is that a cross-sectional correlation exists between the amount of seasonal variation in $x_{1}$ and the amount of non-seasonal variation in $x_{2}$. For example, if preference shifts are quantitatively important over both the seasonal cycle and the business cycle, consumption will tend to be volatile both seasonally and non-seasonally.

The other condition is that a cross-sectional correlation exists between $f_{1}$ and $f_{2}$, which means that sectors in which the effect of $x_{1}^{s}$ on $y^{s}$ is large coincide with those in which the effect of $x_{2}^{n}$ on $y^{n}$ is large. This is the statement that the mechanism transmitting seasonal variation is similar to that producing business cycle variation. ${ }^{3}$

The evidence presented in Figures 1 and 2 therefore suggests that either the mechanism or the type of shock responsible for seasonal variation is also responsible for the business cycle variation. Thus, the determination that a particular phenomena occurs over the seasonal cycle should affect the prior that this same phenomenon occurs over the business cycle.

\footnotetext{
${ }^{3}$ As noted in Beaulieu, MacKie-Mason, and Miron (1992), non-linearity in the relation between $y$ and the $x$ 's can also produce a cross-sectional correlation between the seasonal and non-seasonal standard deviations of $y$, but the correlation can be of either sign. Since the observed correlation is consistently positive, it is unlikely that non-linearities are the main explanation for the results.
} 


\subsection{Seasonal Dummies as Instruments}

A second way to use seasonal cycles to learn about business cycles is to use seasonal dummies as instruments. Consider estimation of the production function

$$
Y_{t}=A_{t}\left(K_{t}^{\alpha} N_{t}^{1-\alpha}\right)^{\gamma}
$$

where $\gamma$ is the parameter of interest. Assume that $A_{t}$ is unmeasured and nonseasonal. Taking logs and treating $A_{t}$ as an error gives a linear estimation equation in which the coefficients on $\log K$ and $\log N$ sum to $\gamma$.

This equation cannot be estimated by OLS because in general $A_{t}$ is correlated with capital and labor. Under the assumption that $A_{t}$ is non-seasonal while $\theta_{t}$ is seasonal, however, seasonal dummies are valid instruments as they are uncorrelated with the error but correlated with the right-hand side variables. The IV approach produces the same coefficient estimates as regressing the seasonal component of output on the seasonal components of capital and labor, but it produces correct standard errors.

In certain circumstances, a researcher may not like the assumption that the orthogonality condition holds in all months. A simple remedy is to pare the list of instruments to those months where the orthogonality condition is 
likely to hold. For instance, one might assume that some weather-induced technology shifts occur in extreme months such as January and July. The monthly dummies for those months can then be excluded from the list of instruments.

\subsection{Interactions Between Seasonal and Non-Seasonal Fluc- tuations}

The final way in which explicit accounting for seasonal fluctuations can enhance understanding of business cycles is that in some contexts seasonal and non-seasonal fluctuations interact. Analysis of models with seasonally adjusted data will involve misspecification, and coefficients on interactions between seasonal and non-seasonal variables can be of particular interest.

To illustrate, consider an alternative version of the production function such that marginal costs are well-approximated by a piece-wise linear function. For example,

$$
M C_{t}=\left\{\begin{array}{l}
2.25 \text { if } Y_{\mathrm{t}} \leq 2.25 \\
Y_{\mathrm{t}} \text { if } \mathrm{Y}_{\mathrm{t}} \geq 2.25
\end{array}\right.
$$

Marginal revenue is given by

$$
M R_{t}=4.5+S_{t}+N S_{t}-Y_{t}
$$

where $S_{t}$ is a seasonal shifter and $N S_{t}$ is a non-seasonal shifter. The seasonal 
shifter alternates, while the non-seasonal shifter has equal probability of being positive or negative. The four possible outcomes for production and marginal costs are given in columns three and four of the table below. A regression that includes two seasonal dummies and two seasonal dummies interacted with $Y_{t}$ will estimate equation (5) consistently.

\begin{tabular}{|c|c|c|c|c|c|c|c|}
\hline \multicolumn{2}{|c|}{ Demand Shifters } & \multicolumn{2}{|c|}{ Unadjusted } & \multicolumn{2}{|c|}{ Non-seasonal } & \multicolumn{2}{|c|}{$\underline{\text { Seasonal }}$} \\
\hline$S$ & $\overline{N S}$ & $Y$ & $M C$ & $Y$ & $M C$ & $Y$ & $M C$ \\
\hline-1.0 & -.5 & .75 & 2.25 & 1.50 & 2.50 & -.75 & -.25 \\
\hline-1.0 & .5 & 1.75 & 2.25 & 2.50 & 2.50 & -.75 & -.25 \\
\hline 1.0 & -.5 & 2.50 & 2.50 & 1.75 & 2.25 & .75 & .25 \\
\hline 1.0 & .5 & 3.00 & 3.00 & 2.25 & 2.75 & .75 & .25 \\
\hline
\end{tabular}

If instead one uses the seasonally adjusted data (where adjustment is regression on seasonal dummies), one will not find a non-linearity in the marginal cost curve and will estimate a slope equal to 0.2 . If one restricts the analysis to the seasonal component - that is, if one uses seasonal dummies as instruments - one will estimate a slope equal to $1 / 3$.

\section{Seasonal Fluctuations as Suggestive Phenom- ena}

Having discussed in theory how accounting for seasonality can aid analysis of business cycles, we now review some of what macroeconomists have learned from the study of seasonal cycles. This section reviews those conclusions 
provided by determining the presence or absence of particular phenomena over the seasonal cycle and then asking whether the answer applies to business cycles as well.

\subsection{Preference Shifts Are an Important Source of Economic Fluctuations}

A first conclusion about business cycles suggested by the nature of seasonal cycles themselves is that preference shifts are an important source of aggregate fluctuations. Table 1 presents the seasonal patterns in quarterly data on the log growth rate of real GDP in OECD countries. ${ }^{4}$ In most countries, the seasonal behavior of GDP is dominated by fourth quarter increases and first quarter declines. The dominant fourth quarter boom implies that a "Christmas" demand shift is an important factor in producing seasonal fluctuations.

Table 2 demonstrates this point more directly by displaying the seasonal patterns in real retail sales for OECD countries. The most dramatic feature is a large positive growth rate in December followed by a large negative growth rate in January, with this pattern consistent across Northern and Southern Hemisphere countries. Braun and Evans (1994) provide more

\footnotetext{
${ }^{4}$ Unless otherwise noted, the results are from Barsky and Miron (1989), or Beaulieu and Miron (1990, 1991, 1992).
} 
formal evidence for this point by estimating structural models that allow for seasonal shifts in preferences. Their results indicate that the seasonals in preference orderings, especially a fourth quarter increase, are similar in magnitude and timing to the observed seasonals in aggregate, quarterly consumption data. Thus, aggregate seasonal fluctuations appear more consistent with demand shifts than technology shifts.

To see why this finding suggests that preference shifts are an important source of business cycle fluctuations consider the standard permanent income model of consumption. Assume that a representative consumer faces the problem:

$$
\max _{C_{t}} E_{t} \sum_{t=0}^{\infty} \beta^{t} U_{t}\left(C_{t}\right)
$$

subject to

$$
\begin{aligned}
A_{t+1} & =R\left(A_{t}+y_{t}-C_{t}\right) \\
A_{0} & =\bar{A}_{0} \\
R \beta & =1,
\end{aligned}
$$

where $C_{t}$ is consumption, $y_{t}$ is income, $A_{t}$ is beginning-of-period wealth, $R$ is the gross real interest rate, and $\beta$ is the rate of time preference.

Suppose the utility function is quadratic with a seasonal shifter in the 
intercept of the marginal utility function,

$$
U_{t}\left(C_{t}\right)=\alpha_{t} C_{t}-\sigma C_{t}^{2}
$$

where $\alpha_{t}$ is a seasonal dummy process. Then the solution for the change in consumption is

$$
C_{t}-C_{t-1}=\frac{1}{2 \sigma}\left(\alpha_{t}-\alpha_{t-1}\right)+\frac{R-1}{R} \sum_{s=t}^{\infty} R^{-(s-t)}\left(\mathrm{E}_{t} y_{s}-\mathrm{E}_{t-1} y_{s}\right)
$$

The variance of the non-seasonal change in consumption depends only on $R$ and the properties of $y_{t}$. The variance of the seasonal change depends only on $\sigma$ and the properties of $\alpha_{t}$.

Thus, if non-seasonal preference shifts are absent, countries with substantial variability in the seasonal component of consumption do not necessarily have substantial variability in the non-seasonal component. Beaulieu, MacKie-Mason and Miron (1992), however, document a strong correlation across countries between the seasonal and non-seasonal variability of retail sales. One explanation is simply that countries with substantial variability in the seasonal component of preference shifts also have substantial variability in the non-seasonal component of preference shifts. 


\subsection{Synergies Play an Important Role in Generating Large Aggregate Fluctuations}

A second conclusion about business cycles provided by the example of seasonal cycles is that synergies play a substantial role in generating fluctuations in output.

Table 3 provides evidence of synergistic agglomeration over the seasonal cycle by presenting seasonal patterns in manufacturing output for the United States and other OECD countries. The striking result is a "summer" slowdown that is present in all Northern Hemisphere countries, particularly those in Western Europe.

A plausible explanation for this slowdown is that synergies across firms or workers make it optimal to have all activity shut down at the same time (Cooper and Haltiwanger (1992), Hall (1991)). Firms might find it desirable to coordinate with upstream or downstream partners to avoid holding extra inventories. Similarly, firms might wish to have all workers on vacation simultaneously to facilitate retooling or maintenance (Cooper and Haltiwanger, 1993b), and different workers in the same family might wish to vacation together.

It is less likely the summer slowdown results mainly from weather in- 
duced changes in the technology. The slowdown is often highly concentrated in a single month, and it is large compared to any obvious change in the weather. Further, the timing of the slowdown (July versus August) differs across countries with identical peaks and troughs in temperature.

The conclusion that weather is not the whole story does not mean weather plays no role. Instead, weather probably pins down the timing of the slowdown as July or August, either because preferences for summer vacations raise the shadow cost of labor or because weather raises marginal production costs (e..g, air conditioning). The weather, however, does not account for the magnitude of the output decline. The fact that Australia displays a slowdown in manufacturing during the Southern Hemisphere summer period is consistent with this discussion.

Cooper and Haltiwanger (1993a) discuss a different example of a seasonal synergy. Before the National Industrial Recovery Act of 1935, automakers retooled for the new model year during the slowdown just before the winter auto shows. This timing created large seasonals in employment and cash flows in locations dominated by automobile production. Individual automakers considered moving the retooling period, but they were dissuaded 
by the practices of others. When the NIRA attempted to mandate smooth employment over the seasons, the retooling period moved permanently to the late summer/early fall even though the Supreme Court voided the NIRA in 1934 . Not only did this move change the seasonal pattern of production, employment and productivity in the automobile industry, it also affected the seasonal pattern in supplier industries like iron and steel. This episode suggests that the seasonal pattern in production does not depend only on simple seasonal fundamentals such as weather, vacation preferences, and the like.

The finding of synergies in production over the seasonal cycle does not by itself prove that synergies are present or important over the business cycle. The cross-sectional correlation in seasonal and non-seasonal variability of output documented in Figures 1 and 2, however, provides a presumption in this direction. If the volatility of output seasonally were due to synergies and the volatility of output non-seasonally were due to other factors, this cross-sectional correlation would arise only with low probability. 


\section{Seasonal Dummies as Instruments}

We now turn to conclusions about business cycles provided by the use of seasonal dummies as instruments.

\subsection{Short Run Productivity Fluctuations are Dominated By Unmeasured Movements in Labor and Capital Utiliza- tion}

A first conclusion provided by the use of seasonal dummy IV is that short-run productivity fluctuations are dominated by movements in labor and capital utilization. A robust fact about business cycles is that output is excessively elastic with respect to labor input. One school of thought holds that the implied fluctuations in productivity result from fluctuations in technology, while a different school argues that labor hoarding, perhaps combined with variation in the rate of capital utilization, explains this stylized fact. Another possible explanation is increasing returns.

As discussed above, resolution of this issue is hampered by the difficulty of accounting explicitly for technology shifts. Optimal employment decisions lead to a correlation between $\log \left(N_{t}\right)$ and the regression error. As argued above seasonal dummies provide a reasonable set of instruments, as they are correlated with labor but not productivity. 
Table 4 examines the seasonal elasticity of output with respect to labor input. ${ }^{5}$ The column labeled Seasonal shows the estimated coefficient on labor input from IV regressions of output on labor input using seasonal dummies as the only instruments. The column labeled Non-Seasonal shows the coefficient on labor input from OLS regressions of output on labor input, with seasonal dummies included in the regression. Labor input is defined as average weekly hours of production workers times the number of production workers.

The seasonal variation in output is highly elastic with respect to the seasonal variation in production-worker hours for manufacturing as a whole, as well as for the subcategories of durables and non-durables. The result is robust across industries, with eleven industries displaying an elasticity significantly above one. Even in industries where labor productivity is not procyclical, the elasticity generally exceeds labor's share in output (Hubbard (1986)), contrary to the implications of constant returns.

In light of the discussion above about the causes of the seasonal movements in production, we find it difficult to account for the high elasticity

\footnotetext{
${ }^{5}$ The output measure used in these results is $Y$, which equals real shipments less changes in inventories. See Beaulieu and Miron (1990) for a fuller discussion of its construction.
} 
purely as the result of aggregate technology shocks, assuming constant returns. Some part of the excess elasticity must result from variation in capital utilization, since the capital stock cannot change much over the seasons. Under constant returns, however, this factor does not explain why some estimated elasticities are well above one. We cannot exclude increasing returns, and Braun and Evans (1991) find an important role for both increasing returns and labor hoarding in explaining the quarterly seasonal behavior of the U.S. economy. Thus, we find it most likely that labor hoarding and variation in capital utilization, perhaps combined with increasing returns, play significant roles in explaining the excess elasticity over the seasonal cycle. Assuming little seasonality in pure technology shocks and little structural changes to the production function over the seasons, these conclusions apply to the business cycle as well.

\subsection{Manufacturing Firms Do Not Smooth Production}

A second conclusion about business cycles suggested by the use of seasonal dummy IV is that manufacturing firms do not smooth production in the face of demand fluctuations. As documented by Blinder (1986) and others, production is usually more variable than sales over the business cycle, and the 
covariance of production and inventory investment is often positive. These facts pose a challenge for the production smoothing model of inventories.

Attempts to evaluate the production smoothing model are hampered, however, by the difficulty of accounting for the behavior of cost shocks over the business cycle. The data fail to reject models with unobservable cost shocks (Eichenbaum, 1989), but they do reject models with observable cost shocks (Miron and Zeldes, 1988). Thus, analyses limited to business cycle fluctuations are not conclusive.

Accounting for the behavior of costs is less problematic with respect to the seasonal cycle. Although some variation in costs over the seasons certainly occurs, a number of a priori restrictions on this seasonality are plausible as well. By noting whether possible deviations of the seasonal behavior of production and sales correspond to plausible seasonal fluctuations in costs, one potentially obtains more compelling evidence on the model than that provided by the business cycle variation.

Figures 3 and 4 demonstrate that production and sales move closely over the seasonal cycle as well as over the business cycle. The figures present estimates of the seasonals in production and shipments for all twenty-three 
2-digit industries and aggregates in the United States and for a number of countries. Each picture plots the seasonals in the log growth rate of shipments and the log growth rate of production. The figures show that the seasonals in production and shipments are strongly similar in almost every 2-digit industry. ${ }^{6}$

As discussed in Miron and Zeldes (1988), the correlations presented graphically are analogous to results of seasonal dummy IV estimation of firms' first-order conditions in which contemporaneous sales is included as a right-hand side variable. As Miron and Zeldes emphasize, even if seasonality in costs makes it optimal to produce seasonally, the timing of the seasonal in production need not match the timing of the seasonal in sales. Moreover, the seasonals in production, especially the July decrease, are not easily explained as shifts in costs.

Thus, estimation of this equation using seasonal dummies as instruments is valid if the production smoothing model is correct. The coincidence of production and sales over the seasons thus provides striking evidence against the standard production smoothing model of inventory accumulation.

\footnotetext{
${ }^{6}$ Beason (1993) reports a similar finding for monthly, disaggregated physical units data for Japanese manufacturing industries.
} 
Some have argued that restricting the analysis only to manufacturing misses important inventory stocks held by retail and wholesale establishments. Inventory technology may make it optimal for sellers to hold excess inventories for smoothing, while finished goods inventories held by manufacturers are simply delays in shipments. Data availability precludes a careful examination of this topic, as retail sales and inventory data are not available by product type. Three points, however, argue against retail and wholesale establishments explaining all the apparent lack of smoothing. First, the seasonals in production seem excessive if production smoothing were possible and desirable. Second, manufacturers ship to many different distributors, and idiosyncratic shocks among the agents would seem to make coordination difficult. Third, the average ratio of inventories to shipments in all of manufacturing in 1994 was 1.4 months, which seems a lot if inventories are merely delayed shipments.

\section{Interactions Between Seasonals and Non-Seasonal Fluctuations}

In this section we review some of what macroeconomists have learned from the interactions between seasonal and business cycle fluctuations. One pos- 
sible reason for interactions is non-linear marginal costs, which imply that the impact of a given size demand shock depends on the initial location of the marginal revenue curve. With seasonal shifts in demand, the impact of a demand shock depends on the season in which it occurs. The exact nature of the interaction depends on the nature of the non-linearity in marginal cost, as well as on the ability of firms to smooth production via inventories. Unless the marginal cost curve is linear, however, one ought to observe season dependent effects of demand on output.

\subsection{Seasonal Heteroskedasticity}

Beaulieu, Mackie-Mason, and Miron (1992) test one implication of nonlinear marginal costs curves, that output should be seasonally heteroskedastic. A given sized demand shock has a larger impact on output in the flatter portions of the marginal cost curve. Moreover, they investigate the type of nonlinearity. If marginal cost curves are convex, the variance of output is inversely related to the seasonal level of output. Beaulieu, Mackie-Mason and Miron test this prediction using three measures of output: IP across countries, IP across U.S. manufacturing industries, and Y4 across U.S. manufacturing industries. 
Their results are reproduced in Table 5. The column labeled Heteroskedasticity gives the results of a White (1980) test for any form of seasonal heteroskedasticty. At the 5 percent level, the data reject the null of no seasonal heteroskedasticity for eighteen of twenty countries (IP) and fourteen (IP) or seventeen (Y4) of twenty U.S. manufacturing industries.

The Spearman rank correlations between the seasonal levels of production and the seasonal variances in the growth rates are reported under the column headed Pattern. For all three production series, eighteen of the twenty countries or industries display negative correlations between the seasonal variance of output and the seasonal level of output. For countries, ten of the correlations are significant at the 5 percent level and three more are significant at the 10 percent level. For industries, with output measured by IP, eight of the correlations are significant at 5 percent and two more are significant at 10 percent. For industries with output measured by Y4, four of the correlations are significantly negative at 5 percent and another two are significant at 10 percent. The percentage of negative rank correlations is substantially larger than under the null of no relationship. This conclusion applies even if countries or industries are not fully independent observations. 


\subsection{Interactions with Demand}

Cecchetti, Kashyap and Wilcox (1994) explore a second implication of nonlinear marginal cost curves. Firms with curvature in their marginal cost functions react differently to stochastic shocks depending on the season, and firms' responses to regular seasonal shifts depend on the state of the business cycle. These dependencies mean that the seasonal pattern in production varies over the business cycle, where the direction of the effect depends on the curvature of the marginal cost curve. In some specifications, such as the capacity model in Beaulieu, MacKie-Mason and Miron (1992), peaks in the seasonal cycle are shaved off in expansions; in other specifications the seasonal is amplified.

CKW test this implication on disaggregated seasonally unadjusted U.S. manufacturing data. They regress the growth rates of production on a constant, an expansion indicator, the square of the expansion indicator, the change in eleven seasonal dummies and the change in the seasonal dummies interacted with an expansion indicator. The indicator they use is the seasonally adjusted capacity utilization index for total US manufacturing lagged one month. Using monthly two-digit industrial production indices, 
they reject the null of no interaction in nearly all industries.

They go further, however, and explore the direction of the interaction. If the marginal cost curve slopes up at an increasing rate, the seasonal cycle is muted in expansions. Seasonal peaks are shaved off, and production increases are concentrated in low activity months. The coefficient on each monthly dummy interacted with an expansion indicator should have a sign different from the coefficient on the monthly dummy alone, after the means of the coefficients over the season are subtracted. For instance, production in high activity months would increase less than in the average month in an expansion. The coefficient on this month's dummy interacted with the expansion dummy should be less than the average of all the coefficients on the interaction terms. Because the month is a high activity month, the coefficient on the dummy alone is higher than the average of the coefficient on the seasonal dummies. The product of the two is negative.

CKW find that in eight of twenty industries seven or more of the eleven independent products are negative. ${ }^{7}$ In only two industries can CKW reject the hypothesis that all of the products are negative: electrical machinery

\footnotetext{
${ }^{7}$ We have computed results analogous to those in CKW using Shea's (1993) instruments for demand curves as the measures of the state of the business cycle. We obtain results similar to those discussed above.
} 
and transportation equipment. That transportation equipment does not support upward sloping convex cost curves is consistent with Krane and Wascher (1995) who find that automakers extend regular seasonal downtimes in recessions. Start-up costs, a form of increasing returns, can rationalize this interaction. ${ }^{8}$

The interaction results and the evidence in Section 4 on labor productivity and production smoothing paint a consistent picture of marginal costs. Firms have unemployed capital and labor that they can use cheaply up to a point. Away from peak production, marginal costs are flat, so production and sales move together. At full production, which occurs in high-activity months near peaks in the business cycle, further production increases are expensive, and marginal costs slope upwards. Firms rarely hit peak seasonal and non-seasonal production simultaneously, so inventories are rarely used to smooth production and are presumably held for other reasons.

\footnotetext{
${ }^{8} \mathrm{CKW}$ also investigate the possibility that the negative products are generated by shifts in demand and not curvature in the marginal cost curve. Using inventory data, they find that some of their results could be generated from shifts in demand.
} 


\section{Conclusions}

The purpose of this paper has been to assess what macroeconomists have learned from the study of seasonal fluctuations. We have suggested that the behavior of seasonal fluctuations provides substantial evidence on the nature of business cycle fluctuations.

We conclude by emphasizing that our discussion of this subject is not meant to be exhaustive. Much other work has been done along these lines, and we believe much more is left to be done. We have focussed on specific conclusions that seem important and that are familiar to us. Our hope, however, is that the arguments we have made about the potential value of the study of seasonal fluctuations will spur others to use seasonality to learn about business cycles. 


\section{References}

[1] Barsky, Robert B. and Jeffrey A. Miron, "The Seasonal Cycle and the Business Cycle," Journal of Political Economy 97 (June 1989), 503-35.

[2] Beason, Dick, "Tests of Production Smoothing in Selected Japanese Industries," Journal of Monetary Economics 31 (June 1993), 381-394.

[3] Beaulieu, J. Joseph, Jeffrey K. MacKie-Mason, and Jeffrey A. Miron, "Why Do Countries and Industries with Large Seasonal Cycles Also Have Large Business Cycles?," Quarterly Journal of Economics CVII (May 1992), 621-656.

[4] Beaulieu, J. Joseph and Jeffrey A. Miron, "Seasonality in U.S. Manufacturing," NBER Working Paper \#3450, 1990.

[5] Beaulieu, J. Joseph and Jeffrey A. Miron, "The Seasonal Cycle in United States Manufacturing," Economics Letters 37 (October 1991), 115-118.

[6] Beaulieu, J. Joseph and Jeffrey A. Miron, "A Cross Country Comparison of Seasonal Cycles and Business Cycles," Economic Journal 102 (July 1992), 772-788. 
17] Beaulieu, J. Joseph and Jeffrey A. Miron, "Seasonal Unit Roots and Deterministic Seasonals in Aggregate U.S. Data," Journal of Econometrics 55 (March 1993), 305-328.

[8] Blinder, Alan, "Can the Production Smoothing Model of Inventory Behavior be Saved?," Quarterly Journal of Economics 101 (August 1986), 431-53.

[9] Braun, R. Anton and Charles L. Evans, "Seasonality and Equilibrium Business Cycle Theories," Journal of Economic Dynamics and Control 19 (April 1994), 503-531.

[10] Braun, R. Anton and Charles L. Evans, "Seasonal Solow Residuals and Christmas: A Case for Labor Hoarding and Increasing Returns," Working Paper \#91-20, Federal Reserve Bank of Chicago, 1991.

[11] Burns, A.F. and W.C. Mitchell, Measuring Business Cycles, (New York: NBER, 1946).

[12] Bursk, J. Parker, Seasonal Variations in Employment in Manufacturing Industries: A Statistical Study Based on Census Data, (Philadelphia: University of Pennsylvania Press, 1931). 
[13] Cecchetti, Stephen C., Anil K. Kashyap, and David W. Wilcox, "Why Firms Smooth the Seasonal in Production During a Boom," manuscript, Ohio State University, 1994.

[14] Chatterjee, Satyajit and B. Ravikumar, "A Stochastic Growth Model with Seasonal Perturbations," Journal of Monetary Economics 29 (February 1992), 59-86.

[15] Cooper, Russell and John Haltiwanger, "Automobiles and the National Industrial Recovery Act: Evidence on Macroeconomic Complementarities," Quarterly Journal of Economics CVIII (November 1993a), 1043-71.

[16] Cooper, Russell and John Haltiwanger, "The Macroeconomic Implications of Machine Replacement: Theory and Evidence," American Economic Review 83 (June 1993b), 360-382.

[17) Cooper, Russell and John Haltiwanger, "Macroeconomic Implications of Production Bunching: Factor Demand Linkages," Journal of Monetary Economics 30 (October 1992), 107-127.

[18] Eichenbaum, Martin, "Some Empirical Evidence on the Production Level and Production Cost Smoothing Models of Inventory Investment," 
American Economic Review 79 (September 1989), 853-64.

[19] Ghysels, Eric, "A Study Toward a Dynamic Theory of Seasonality for Economic Time Series," Journal of the Americal Statistical Association 83 (March 1988), 168-72.

[20] Hall, Robert E., Booms and Recessions in a Noisy Economy, (New Haven: Yale University Press, 1991).

[21] Hubbard, R. Glenn, "Comment," Brookings Papers on Economic Activity 2 (1986), 328-336.

[22] Kemmerer, Edwin W., Seasonal Variations in the Relative Demand for Money and Capital in the United States: A Statistical Study, (Washington, D.C.: Government Printing Office, 1910).

[23] Krane, Spencer and William Wascher, "The Cyclical Sensitivity of Seasonality in U.S. Employment," manuscript, Board of Governors of the Federal Reserve System, 1995.

[24] Kuznets, Simon, Seasonal Variations in Industry and Trade, (New York: NBER, 1933). 
[25] Macaulay, Frederick R, Some Theoretical Problems Suggested by Movements of Interest Rates, Bond Yields, and Stock Prices in the United States Since 1856, (New York: NBER, 1938).

[26] Miron, Jeffrey A. and Stephen P. Zeldes, "Seasonality, Cost Shocks, and the Production Smoothing Model of Inventories," Econometrica 56 (July 1988), 877-908.

[27] Shea, John, "The Input-Output Approach to Instrument Selection," Journal of Business and Economic Statistics 11 (April 1993), 145-155.

[28] White, Halbert, "A Heteroskedasticity-Consistent Covariance Matrix Estimator and a Direct Test for Heteroskedasticity," Econometrica 48 (May 1980), 817-838. 
Table 1: Seasonal Patterns, Real GDP

\begin{tabular}{lrrrr}
\hline & Q1 & \multicolumn{1}{c}{ Q2 } & \multicolumn{1}{c}{ Q3 } & \multicolumn{1}{c}{ Q4 } \\
\hline Argentina & -6.09 & 2.53 & -.39 & 3.95 \\
Australia & -14.37 & .09 & 4.05 & 10.23 \\
Austria & -15.60 & 6.52 & 5.66 & 3.42 \\
Canada & -6.76 & 4.59 & 7.49 & -5.32 \\
Finland & -12.38 & 4.50 & 1.39 & 6.49 \\
Germany & -7.61 & 3.24 & 4.64 & -.27 \\
Italy & -9.57 & 4.72 & .78 & 4.07 \\
Japan & -17.22 & .05 & 5.40 & 11.77 \\
Netherlands & -4.04 & 6.41 & -6.31 & 3.93 \\
Norway & -4.17 & -2.18 & 2.78 & 3.57 \\
Sweden & -9.38 & .42 & -9.81 & 18.76 \\
Taiwan & -3.54 & 1.02 & -2.87 & 5.39 \\
United King. & -5.90 & 1.65 & 1.22 & 3.03 \\
United States & -8.17 & 3.96 & -.56 & 4.77 \\
\hline
\end{tabular}


Table 2: Seasonal Patterns, Real Retail Sales

\begin{tabular}{|c|c|c|c|c|c|c|c|c|c|c|c|c|}
\hline & $J A N$ & $F E B$ & $M A R$ & $\overline{A P R}$ & $M A Y$ & JUN & JUL & $A U G$ & $S E P$ & $\overline{O C T}$ & NOV & $\overline{D E C}$ \\
\hline Australia & -33.77 & -5.70 & 7.15 & -.41 & 6.63 & -7.80 & 2.27 & .66 & -1.03 & 4.40 & 2.82 & 24.77 \\
\hline Austria & -52.38 & -2.66 & 13.54 & .05 & -.08 & -.77 & 4.80 & -1.46 & -.47 & 6.81 & 3.08 & 29.53 \\
\hline Belgium & -27.28 & -3.88 & 14.56 & .12 & .34 & 1.46 & -11.67 & -.50 & 7.37 & 3.62 & -6.78 & 22.65 \\
\hline Canada & -36.61 & -4.27 & 14.59 & 4.66 & 6.41 & -1.71 & -4.95 & -1.99 & -.89 & 5.57 & 2.49 & 16.70 \\
\hline Denmark & -30.17 & -10.79 & 9.00 & 1.04 & 4.89 & -1.86 & 2.48 & -1.64 & -4.14 & 4.49 & -2.40 & 29.11 \\
\hline Finland & -43.50 & 1.22 & 3.54 & 11.27 & 4.97 & -2.69 & -8.85 & -.73 & 2.76 & 2.25 & .47 & 29.29 \\
\hline France & -47.02 & -18.32 & 15.94 & -2.34 & 4.00 & -.13 & -5.15 & -8.67 & 21.62 & 3.18 & -3.02 & 39.92 \\
\hline Germany & -42.20 & -3.34 & 17.26 & -.20 & -2.21 & -4.44 & 3.90 & -7.65 & 3.75 & 11.13 & 3.44 & 20.56 \\
\hline Gree & -23.18 & 2.11 & -9.24 & 12.38 & -9.35 & -2.89 & -4.28 & 4.98 & .53 & 7.28 & 1.75 & 19.91 \\
\hline Italy & -47.07 & -6.65 & 16.36 & -1.42 & .30 & -1.12 & -2.69 & -13.25 & 19.20 & 8.16 & -8.36 & 36.53 \\
\hline Jape & -43.12 & -3.42 & 17.94 & -2.89 & -2.48 & -.39 & 7.85 & -7.95 & -2.36 & 4.96 & .80 & 31.06 \\
\hline Netb & -16.19 & -13.87 & 15.78 & .84 & 3.79 & -4.48 & .48 & -6.50 & 4.45 & 7.74 & .01 & 7.97 \\
\hline Norw & -44.96 & -2.94 & 9.45 & 1.97 & 6.13 & 3.51 & -4.46 & .58 & -.89 & 6.33 & -1.92 & 27.21 \\
\hline New Zealand & -31.44 & .13 & 11.18 & -2.99 & 6.75 & -8.34 & 3.43 & .75 & -.71 & .63 & 2.57 & 18.02 \\
\hline Spain & 10.61 & -54.83 & .14 & 2.03 & 7.13 & 1.83 & 28.90 & -34.23 & 4.51 & 18.23 & -11.41 & 27.10 \\
\hline Sweden & -38.99 & -6.10 & 10.81 & 3.96 & 1.21 & -1.98 & -3.50 & .90 & -.11 & 8.98 & -1.99 & 26.79 \\
\hline Switzerland & -33.40 & -12.79 & 13.53 & 1.28 & -1.69 & -3.32 & -3.19 & -7.54 & 3.32 & 9.56 & 8.36 & 25.89 \\
\hline United King. & -32.78 & -3.85 & 4.07 & 1.37 & .67 & -.92 & 3.18 & -3.09 & .57 & 4.32 & 6.14 & 20.30 \\
\hline United States & -30.65 & -3.50 & 13.12 & 1.16 & 3.85 & -.58 & -2.04 & 1.08 & -4.44 & 4.42 & .27 & 17.31 \\
\hline Yugoslavia & -43.59 & 2.74 & 15.76 & 9.24 & -8.48 & 6.80 & 1.62 & 3.28 & 1.53 & .61 & .02 & 10.46 \\
\hline
\end{tabular}


Table 3: Seasonal Patterns, Industrial Production

\begin{tabular}{|c|c|c|c|c|c|c|c|c|c|c|c|c|}
\hline & $J A N$ & $F E B$ & $M A R$ & $A P R$ & $M A Y$ & JUN & $J U L$ & $A U G$ & $S E P$ & $O C T$ & NOV & $D E C$ \\
\hline Food & -1.53 & 0.86 & 0.80 & 0.43 & 1.19 & 4.37 & -2.27 & 4.01 & 2.44 & -1.70 & -4.77 & -3.83 \\
\hline Tobacco & 23.61 & 5.02 & -4.18 & -4.33 & 0.37 & 9.56 & -20.06 & 20.01 & -2.33 & 4.38 & -6.95 & -25.11 \\
\hline Textiles & 3.99 & 5.69 & 1.70 & 0.21 & 1.08 & 1.84 & -16.05 & 15.80 & -0.07 & 0.87 & -4.34 & -10.72 \\
\hline Apparel & 3.40 & 6.17 & -0.18 & -1.66 & -0.81 & 4.28 & -10.28 & 11.02 & 0.07 & -0.90 & -4.11 & -7.00 \\
\hline Lumber & 0.40 & 7.08 & 1.84 & 1.30 & -0.75 & 4.01 & -6.10 & 6.34 & -0.17 & -0.39 & -6.47 & -7.09 \\
\hline Furniture & -1.40 & 6.33 & -2.93 & -2.60 & -1.81 & 3.01 & -9.82 & 11.59 & 1.76 & -1.42 & -0.65 & -2.07 \\
\hline Paper & 8.06 & 4.46 & 0.07 & -0.83 & -1.83 & 1.57 & -9.74 & 8.05 & -0.70 & 3.96 & -3.90 & -9.16 \\
\hline Printing & -4.83 & 3.46 & 0.86 & 1.49 & 1.65 & 4.40 & 1.43 & 4.31 & 0.92 & -4.01 & -4.39 & -5.28 \\
\hline Chemicals & -1.20 & 2.77 & 0.73 & 0.93 & 0.06 & 3.08 & -2.15 & 0.75 & 2.59 & -2.28 & -2.29 & -2.98 \\
\hline Petroleum & -5.12 & -0.64 & -0.93 & 1.58 & 3.19 & 3.96 & 0.60 & 0.31 & -0.71 & -2.10 & 0.61 & -0.76 \\
\hline Rubber & 0.41 & 8.42 & -1.20 & -1.81 & -2.47 & 1.86 & -9.82 & 8.57 & 4.40 & 0.73 & -3.61 & -5.47 \\
\hline Leather & 3.99 & 6.24 & 0.02 & -3.07 & 0.12 & 1.13 & -16.26 & 16.69 & -0.47 & 2.63 & -3.91 & -7.12 \\
\hline Stone,Clay, Glass & -2.77 & 3.07 & 2.72 & 3.30 & 0.66 & 2.77 & -3.67 & 4.06 & -0.65 & 1.37 & -3.73 & -7.13 \\
\hline Primary Metal & 4.93 & 5.80 & 3.37 & -0.12 & -1.12 & -1.59 & -12.94 & 2.84 & 3.43 & 1.48 & -2.23 & -3.85 \\
\hline Fab Metal & -3.04 & 3.71 & 0.35 & -1.16 & 0.20 & 2.05 & -3.71 & 2.28 & $\cdot 2.14$ & -0.49 & -0.76 & -1.57 \\
\hline Machinery & -0.65 & 3.91 & -0.40 & -1.30 & 0.02 & 3.44 & -2.08 & 0.89 & 2.74 & -2.50 & -1.88 & -2.19 \\
\hline Elec Machinery & -0.09 & 1.13 & 0.28 & -1.26 & 0.26 & 1.28 & -4.88 & 3.50 & 3.85 & 1.43 & -2.40 & -3.09 \\
\hline Trans Equip & 0.55 & 2.15 & 2.20 & -1.35 & 1.18 & 1.82 & -14.08 & -1.25 & 10.29 & 2.61 & -1.44 & -2.67 \\
\hline Instruments & -2.35 & 1.00 & 0.28 & -0.81 & 1.09 & 3.01 & -1.34 & 1.29 & 1.25 & -1.67 & -0.82 & -0.93 \\
\hline Other & -2.48 & 7.22 & -0.01 & -1.49 & 0.11 & 4.43 & -3.92 & 6.40 & 2.17 & -2.98 & -3.75 & -5.70 \\
\hline Non-Durables & 0.18 & 3.45 & 0.35 & 0.11 & 0.29 & 3.48 & -4.82 & 5.18 & 1.86 & -1.11 & -3.65 & -5.32 \\
\hline Durables & -0.32 & 3.26 & 0.88 & -0.77 & 0.21 & 2.00 & -6.28 & 2.15 & 3.61 & 0.10 & -1.94 & -2.90 \\
\hline Total & -0.11 & 3.35 & 0.65 & -0.42 & 0.26 & 2.61 & -5.65 & 3.59 & 2.71 & -0.40 & -2.66 & -3.92 \\
\hline Australia & -21.41 & 33.47 & -.16 & -3.00 & .19 & -.59 & 1.44 & .28 & 2.83 & -.18 & 1.64 & -14.50 \\
\hline Austria & -13.12 & 5.32 & 2.13 & 1.78 & 2.80 & .18 & -13.22 & .57 & 10.00 & 2.36 & 3.80 & -2.59 \\
\hline Belgium & -1.29 & 5.90 & .24 & 1.70 & -.65 & -.84 & -27.11 & 17.67 & 10.78 & .05 & 3.07 & -9.50 \\
\hline Canada & .07 & 6.72 & -.40 & -1.72 & -.65 & 3.38 & -13.70 & 4.36 & 7.78 & .01 & 1.79 & -7.66 \\
\hline Finland & -.03 & 1.29 & -.07 & 2.29 & -.46 & -5.61 & -41.79 & 36.99 & 6.96 & 1.68 & 1.63 & -2.89 \\
\hline France & -.51 & 1.77 & -.39 & -.55 & -2.84 & 1.68 & -12.12 & -36.54 & 45.68 & 3.76 & 1.83 & -1.76 \\
\hline Germany & -8.62 & 6.32 & 1.50 & 1.88 & -1.18 & .61 & -11.79 & -4.58 & 15.84 & 1.74 & 4.29 & -5.99 \\
\hline Greece & -7.19 & 4.93 & 2.30 & -.69 & 1.96 & 4.76 & -1.75 & -3.46 & 8.50 & -4.69 & -1.55 & -3.13 \\
\hline Ireland & -3.61 & 7.87 & 3.94 & -.49 & 1.70 & 3.44 & -9.84 & -13.96 & 18.86 & -.55 & 1.81 & -9.16 \\
\hline Italy & 1.46 & 4.37 & .66 & .25 & .49 & -.29 & -4.30 & -52.17 & 56.58 & -1.04 & 1.48 & -7.48 \\
\hline Japan & -10.88 & 5.78 & 7.93 & -5.56 & -2.21 & 3.27 & .44 & -5.91 & 5.84 & -.60 & -.67 & 2.57 \\
\hline Luxembourg & .26 & 4.98 & .45 & 2.39 & 1.91 & -.70 & -6.02 & -16.56 & 18.50 & -.53 & 1.45 & -6.12 \\
\hline Netherlands & -5.75 & 2.51 & -.64 & -.63 & -3.62 & -1.00 & -17.11 & 5.59 & 10.28 & 6.64 & 3.74 & -.01 \\
\hline Norway & 4.61 & 5.74 & -4.41 & -6.69 & -2.09 & 8.40 & -44.76 & 38.75 & 7.64 & 2.33 & 2.64 & -12.17 \\
\hline Portugal & -1.16 & 2.48 & 1.46 & .97 & -2.64 & .55 & -4.92 & -19.23 & 23.62 & 1.72 & -.34 & -2.50 \\
\hline Spain & -.43 & -.78 & 4.01 & -3.33 & 2.83 & -2.05 & -2.68 & -32.74 & 33.97 & 4.16 & -.24 & -2.72 \\
\hline Sweden & -4.38 & 1.60 & 1.17 & 5.05 & -2.38 & 1.13 & -84.48 & 75.17 & 6.65 & 2.95 & 1.34 & -3.81 \\
\hline United King. & .24 & 6.27 & 1.42 & -7.09 & .92 & .24 & -9.40 & -5.80 & 16.09 & 2.97 & 2.55 & -8.42 \\
\hline United States & .15 & 2.60 & .27 & -.39 & .11 & 2.35 & -5.19 & 3.42 & 2.36 & -.35 & -2.22 & -3.10 \\
\hline Yugoslavia & -17.29 & 4.30 & 10.82 & -3.32 & -1.22 & 2.89 & -17.07 & 9.21 & 7.30 & 4.00 & -5.71 & 6.09 \\
\hline
\end{tabular}


Table 4: Elasticity of Output with Respect to Labor Input

$$
\text { Seasonal }
$$

Non-Seasonal

Coefficient St. Dev. Coefficient St. Dev.

\begin{tabular}{lllll}
\hline Food & 0.568 & .065 & 0.369 & .112 \\
Tobacco & 0.779 & .166 & 0.468 & .170 \\
Textiles & 3.394 & .333 & 0.211 & .066 \\
A pparel & 1.591 & .193 & 0.499 & .191 \\
Lumber & 1.413 & .151 & 0.487 & .234 \\
Furniture & 1.610 & .230 & 0.527 & .163 \\
Paper & 0.154 & .191 & 0.521 & .183 \\
Printing & 0.367 & .260 & -0.188 & .436 \\
Chemicals & 2.204 & .367 & 1.263 & .205 \\
Petroleum & 0.416 & .138 & 0.026 & .033 \\
Rubber & 2.102 & .230 & 0.358 & .094 \\
Leather & 1.210 & .277 & 0.160 & .278 \\
Stone,Clay,Glass & 0.886 & .094 & 0.526 & .085 \\
Primary Metal & 1.366 & .212 & 1.400 & .168 \\
Fab Metal & 1.961 & .275 & 0.549 & .161 \\
Machinery & 4.084 & .361 & 0.595 & .206 \\
Elec Machinery & 3.600 & .039 & 0.372 & .141 \\
Trans Equip & 0.967 & .012 & 0.819 & .102 \\
Instruments & 3.347 & .382 & 0.970 & .309 \\
Other & 1.911 & .193 & 0.092 & .215 \\
Non-Durables & 1.297 & .091 & 0.461 & .104 \\
Durables & 2.077 & .157 & 0.898 & .085 \\
Total & 1.736 & .125 & 0.689 & .088 \\
\hline \multicolumn{2}{l}{} & & &
\end{tabular}


Table 5a: Tests for Heteroskedasticity in Growth Rates - IP, OECD Countries

\begin{tabular}{lcccclrccc}
\hline \multicolumn{1}{c}{ Country } & \multicolumn{2}{c}{ Heteroskedasticity } & \multicolumn{2}{c}{ Pattern } & \multicolumn{2}{c}{ Country } & \multicolumn{2}{c}{ Heteroskedasticity } & \multicolumn{2}{c}{ Pattern } \\
& $\chi_{11}^{2}$ & $p$-value & Correl. & $p$-value & & $\chi_{11}^{2}$ & $p$-value & Correl. & $p$-value \\
Australia & 9.83 & .546 & .420 & .913 & Japan & 30.96 & .001 & -.538 & .035 \\
Austria & 12.69 & .314 & -.147 & .324 & Luxembourg & 140.33 & .000 & -.650 & .011 \\
Belgium & 36.30 & .000 & -.734 & .003 & Netherlands & 92.90 & .000 & -.280 & .189 \\
Canada & 87.35 & .000 & -.469 & .062 & Norway & 64.64 & .000 & -.685 & .007 \\
Finland & 85.71 & .000 & -.650 & .011 & Portugal & 52.38 & .000 & -.105 & .373 \\
France & 77.14 & .000 & -.874 & .000 & Spain & 86.55 & .000 & -.559 & .029 \\
Germany & 58.54 & .000 & -.608 & .018 & Sweden & 112.89 & .000 & -.455 & .069 \\
Greece & 59.93 & .000 & .720 & .996 & United Kingdom & 98.26 & .000 & -.161 & .309 \\
Ireland & 20.52 & .039 & -.685 & .007 & United States & 32.07 & .001 & -.580 & .024 \\
Italy & 67.71 & .000 & -.413 & .091 & Yugoslavia & 41.13 & .000 & -.329 & .148 \\
\hline
\end{tabular}

Table 5b: Tests for Heteroskedasticity in Growth Rates - IP, U.S. Manufacturing Industries

\begin{tabular}{lcccclcccc}
\hline \multicolumn{1}{c}{ Industry } & \multicolumn{2}{c}{ Heteroskedasticity } & \multicolumn{2}{c}{ Pattern } & \multicolumn{2}{c}{ Industry } & \multicolumn{2}{c}{ Heteroskedasticity } & \multicolumn{2}{c}{ Pattern } \\
& $\chi_{11}^{2}$ & $p$-value & Correl. & $p$-value & & $\chi_{11}^{2}$ & $p$-value & Correl. & $p$-value \\
Food & 77.67 & .000 & -.154 & .317 & Stone, Clay, Glass & 26.41 & .006 & -.713 & .005 \\
Tobacco & 23.79 & .014 & -.287 & .183 & Primary Metals & 14.60 & .202 & -.517 & .042 \\
Textiles & 24.19 & .012 & -.776 & .001 & Fabricated Metals & 10.77 & .463 & -.371 & .118 \\
A pparel & 202.64 & .000 & -.685 & .007 & Machinery & 11.31 & .417 & .063 & .577 \\
Lumber & 26.64 & .005 & -.455 & .069 & Electrical Machinery & 34.63 & .000 & -.385 & .109 \\
Furniture & 27.85 & .003 & -.315 & .160 & Transportation Eqp. & 59.71 & .000 & -.804 & .001 \\
Paper & 31.50 & .001 & -.301 & .171 & Instruments & 12.58 & .321 & -.154 & .317 \\
Printing & 39.61 & .000 & .175 & .707 & Miscellaneous Mfg. & 9.28 & .596 & -.587 & .022 \\
Chemicals & 17.58 & .092 & -.448 & .072 & & & & \\
Petroleum & 25.23 & .008 & -.531 & .038 & Non-Durables & 32.47 & .001 & -.007 & .491 \\
Rubber & 21.05 & .033 & -.224 & .242 & Durables & 66.01 & .000 & -.671 & .008 \\
Leather & 45.30 & .000 & -.909 & .000 & Total Manufacturing & 66.24 & .000 & -.573 & .026 \\
\hline
\end{tabular}


Table 5c: Tests for Heteroskedasticity in Growth Rates - Y4, U.S. Manufacturing Industries

\begin{tabular}{lcccclcccc}
\hline \multicolumn{1}{c}{ Industry } & \multicolumn{2}{c}{ Heteroskedasticity } & \multicolumn{2}{c}{ Pattern } & \multicolumn{2}{c}{ Industry } & \multicolumn{2}{c}{ Heteroskedasticity } & \multicolumn{2}{c}{ Pattern } \\
& $\chi_{11}^{2}$ & $p$-value & Correl. & $p$-value & & $\chi_{11}^{2}$ & $p$-value & Correl. & $p$-value \\
Food & 51.01 & .000 & -.294 & .177 & Stone, Clay, Glass & 31.58 & .001 & -.392 & .104 \\
Tobacco & 25.71 & .007 & -.154 & .317 & Primary Metals & 29.34 & .002 & -.035 & .457 \\
Textiles & 33.66 & .000 & .329 & .852 & Fabricated Metals & 35.30 & .000 & -.734 & .003 \\
Apparel & 15.40 & .165 & -.580 & .024 & Machinery & 37.54 & .000 & -.357 & .128 \\
Lumber & 49.94 & .000 & -.448 & .072 & Electrical Machinery & 45.11 & .000 & -.329 & .148 \\
Furniture & 11.03 & .441 & -.182 & .286 & Transportation Eqp. & 28.19 & .003 & -.629 & .014 \\
Paper & 47.63 & .000 & -.448 & .072 & Instruments & 31.16 & .001 & -.028 & .466 \\
Printing & 23.96 & .013 & -.357 & .128 & Miscellaneous Mfg. & 38.03 & .000 & -.329 & .148 \\
Chemicals & 35.02 & .000 & .070 & .585 & & & & \\
Petroleum & 16.14 & .136 & -.273 & .196 & Non-Durables & 17.07 & .106 & -.175 & .293 \\
Rubber & $\mathbf{3 4 . 6 9}$ & .000 & -.629 & .014 & Durables & 42.73 & .000 & -.385 & .109 \\
Leather & 28.49 & .003 & -.182 & .286 & Total Manufacturing & 33.18 & .000 & -.343 & .138 \\
\hline
\end{tabular}




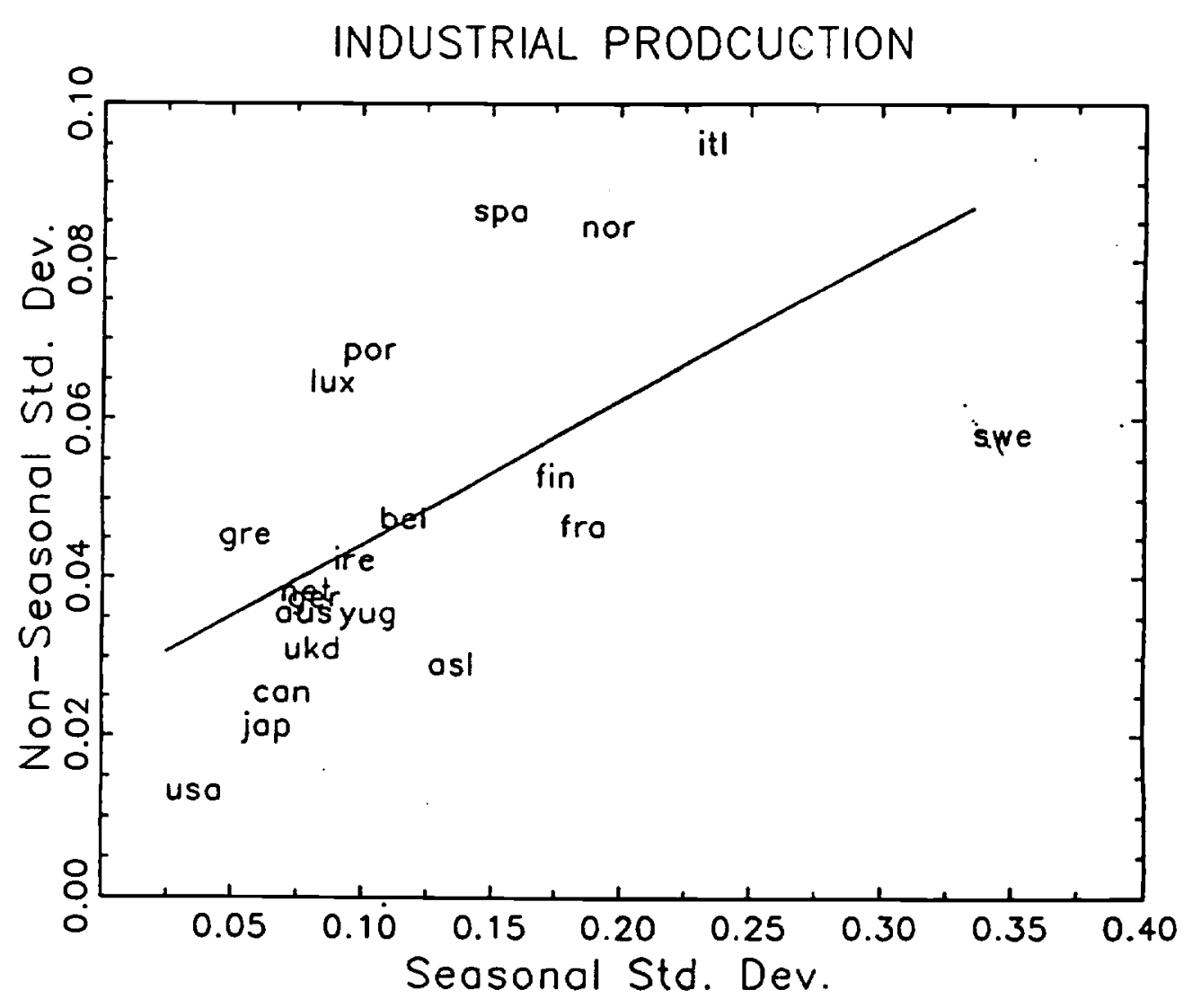

Figure 1

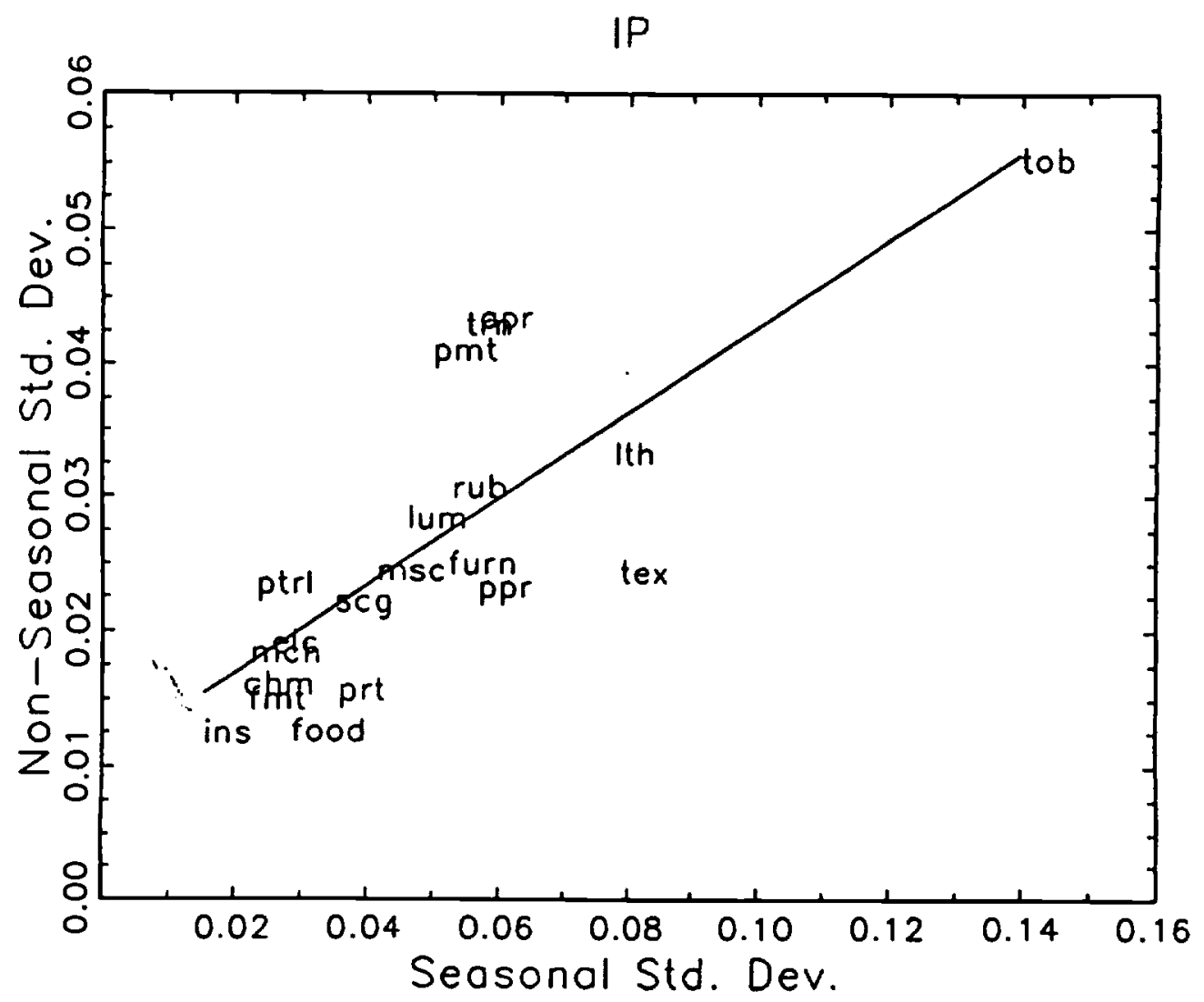

Floure 2 

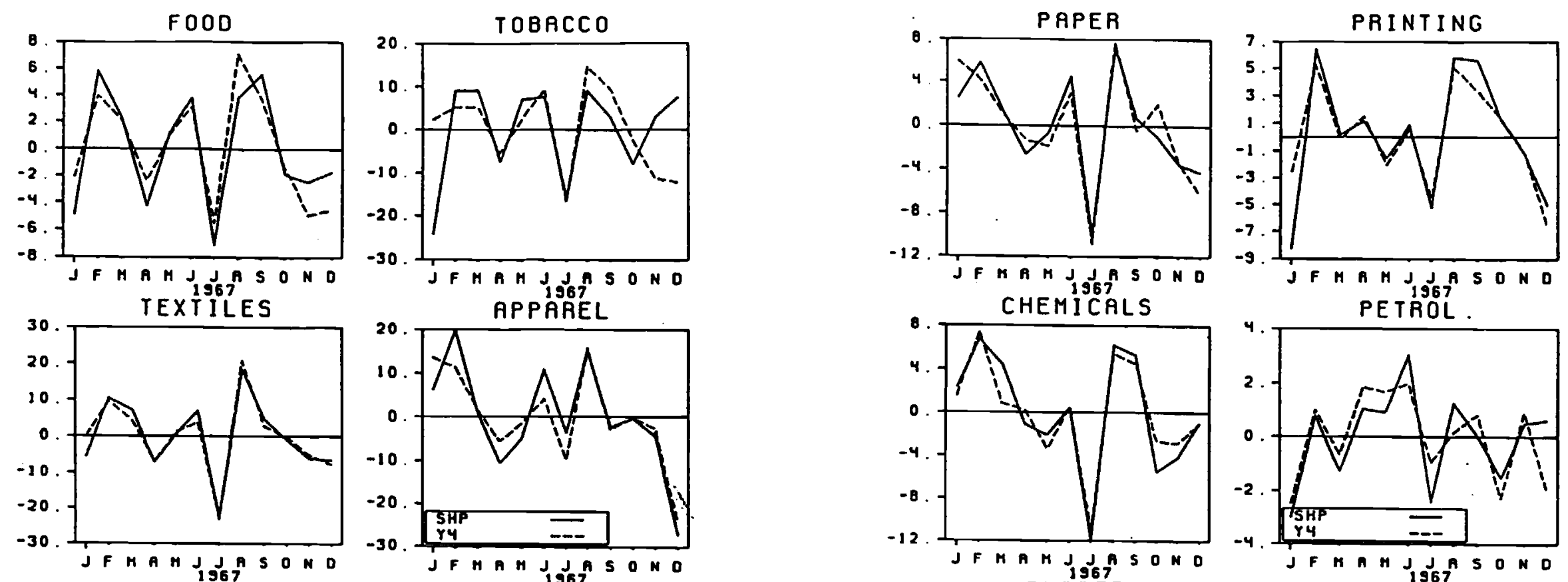

APPRREL
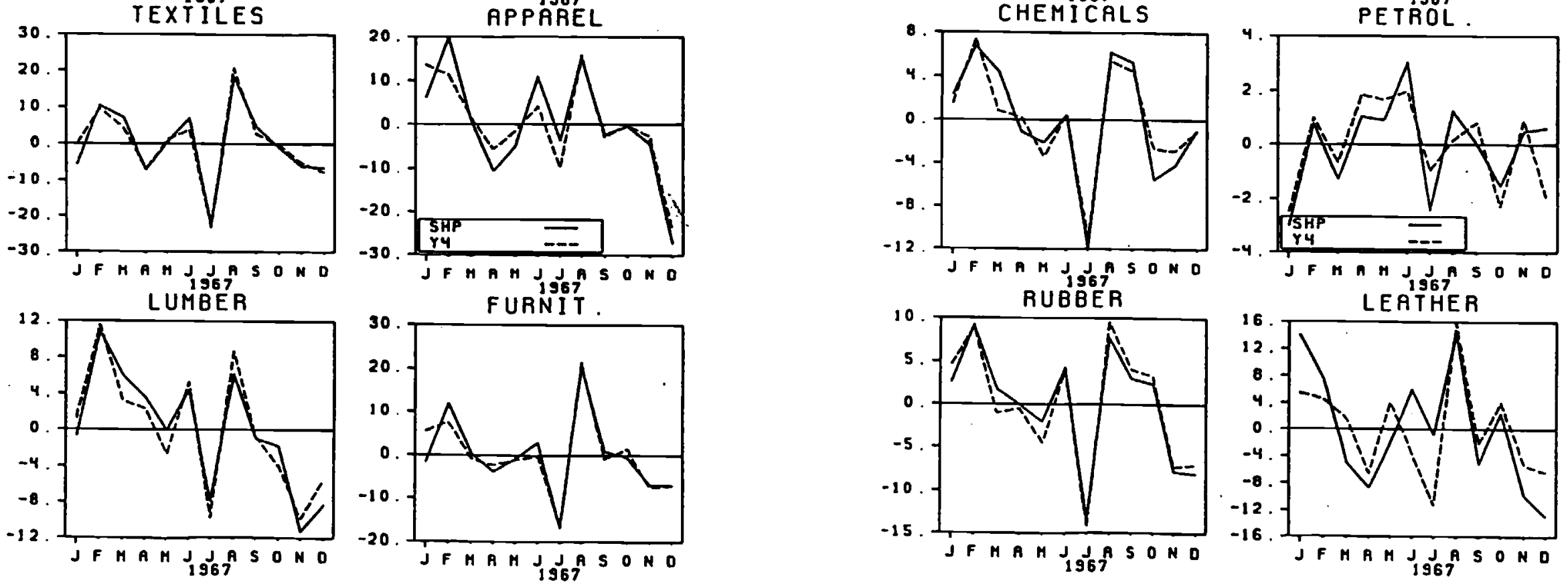

Figure 3 

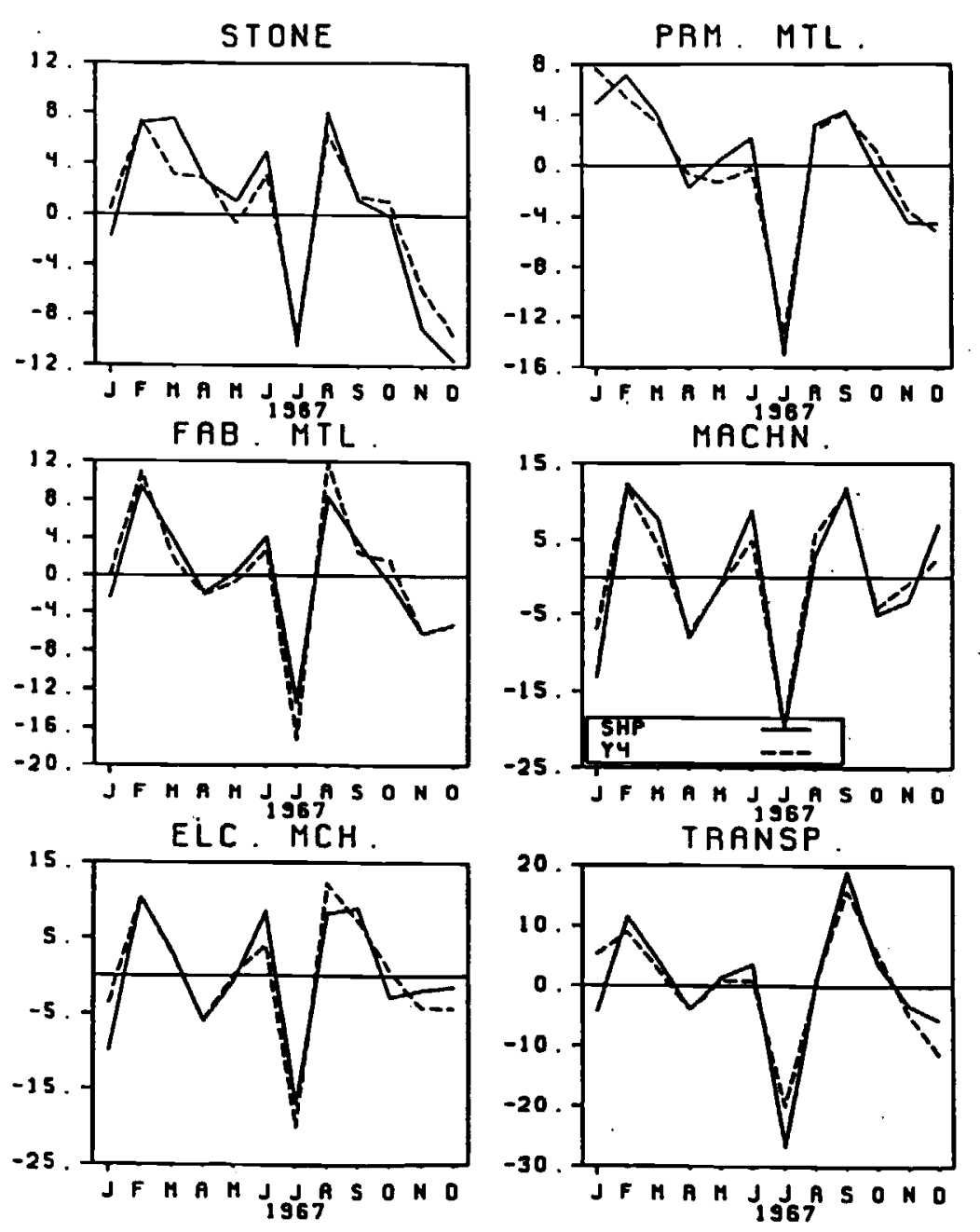
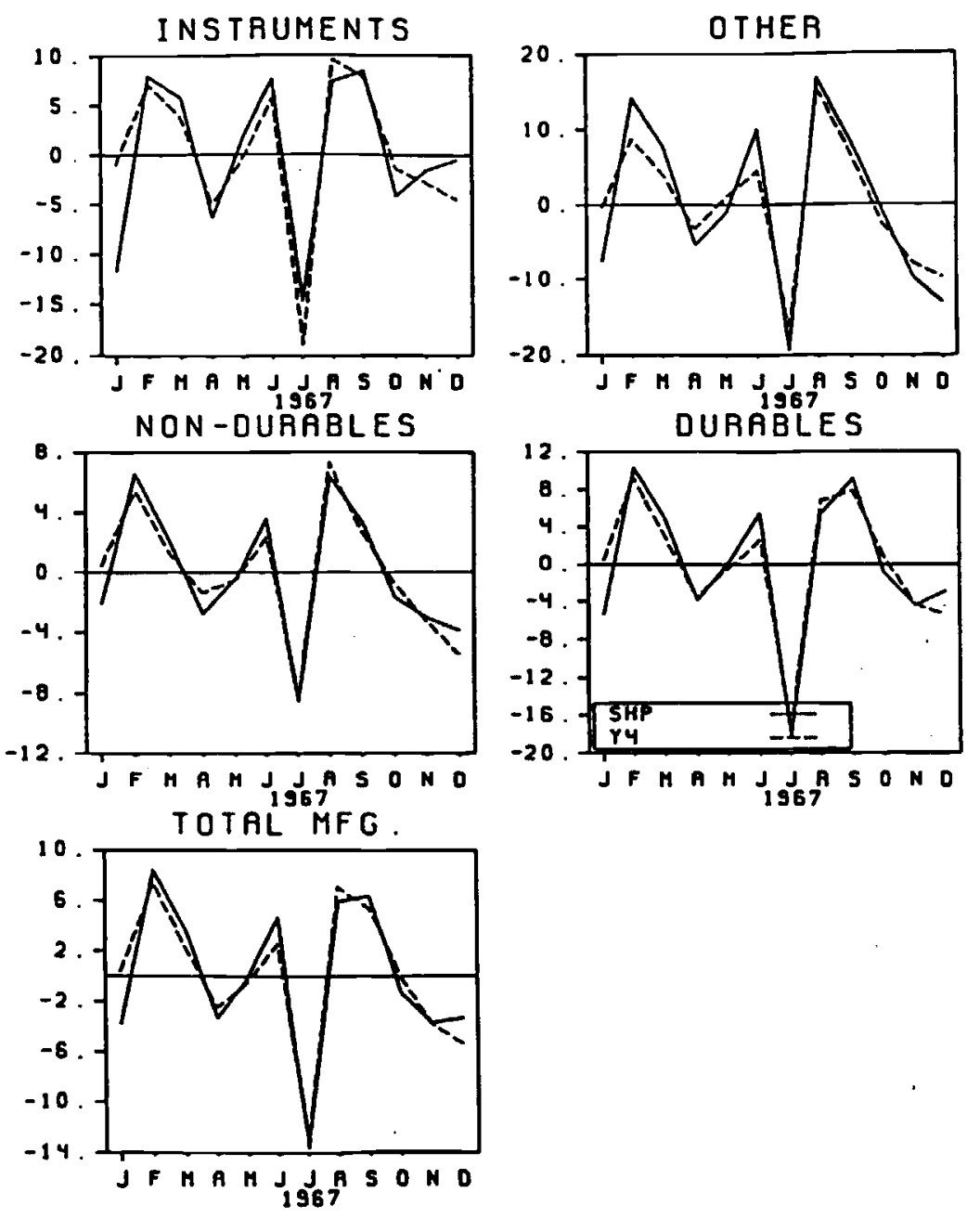

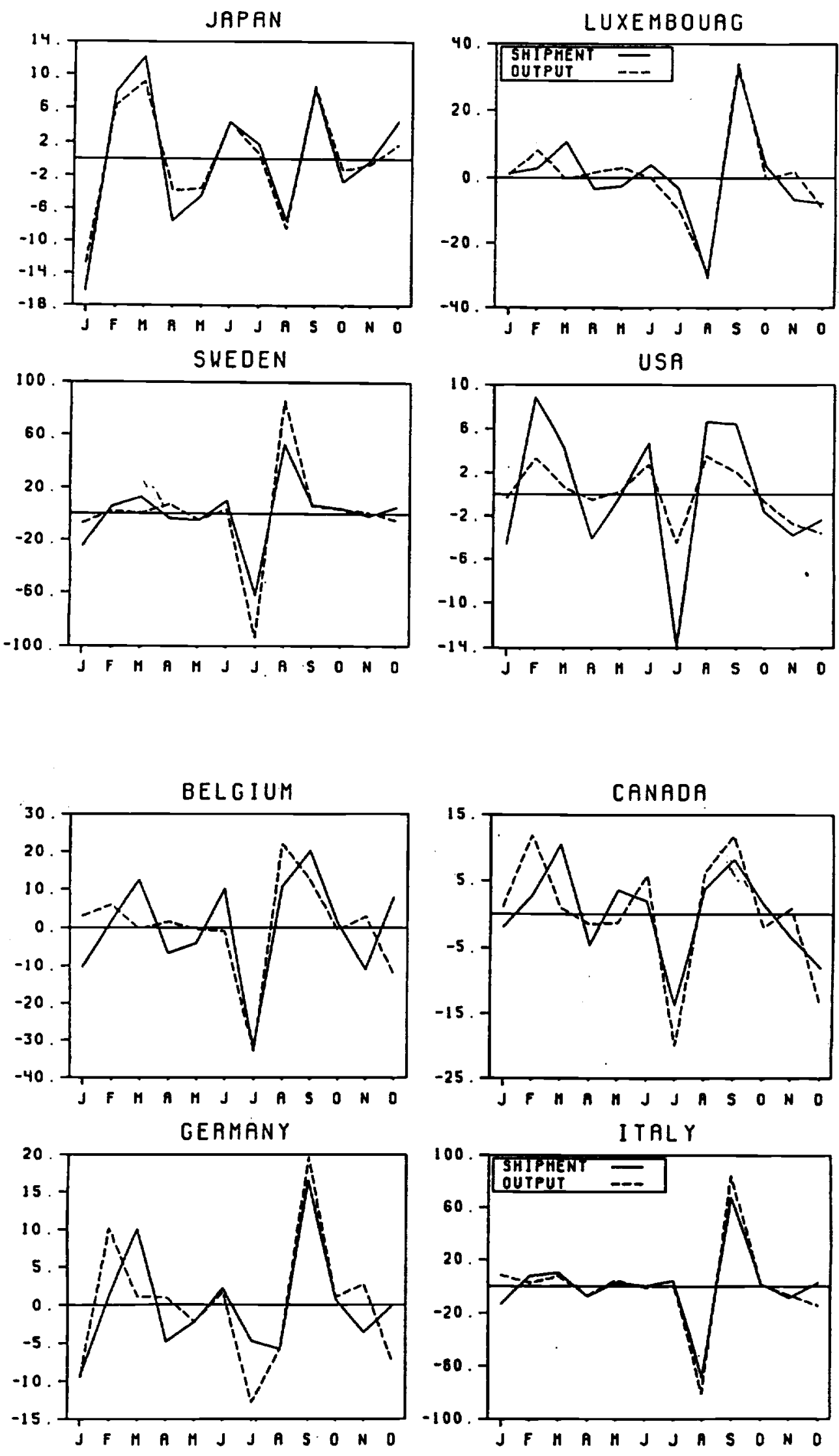